\title{
Stability of Serum/Plasma Glucose for the Diagnosis of Diabetes Mellitus
}

\author{
${ }^{1}$ Nwosu, O. K. and ${ }^{2}$ Nwani, C. D. \\ ${ }^{1}$ Department of Chemical Pathology, Faculty of Clinical Medicine, Ebonyi State University. \\ ${ }^{2}$ Department of Applied Biology, Ebonyi State University. PMB. 053, Abakaliki, Nigeria
}

Corresponding Author: Nwani, C.D. Department of Applied Biology, Ebonyi State University, PMB 053 Abakaliki, Ebonyi State, Nigeria. Email: didigwunwani@yahoo.com.

\begin{abstract}
Due to inconsistent power supply in the developing countries, particularly in the rural areas, immediate sample separation and analysis may not be practicable. This study investigated the time-related changes in glucose concentration of serum and plasma specimens stored at $4^{\circ} \mathrm{C}$ and room temperature $\left(32^{\circ} \mathrm{C}\right)$ for 3 days. Blood samples were collected from 30 fasting patients suffering from diabetes mellitus at the Ebonyi State University Teaching Hospital (EBSUTH), Abakaliki, Nigeria. Glucose levels were assayed using glucose oxidase method immediately upon sample collection and separation to obtain the baseline value $(B V)$ and thereafter at specified time intervals across 72 hours. In serum samples, the values obtained after 2 hours at $32^{\circ} \mathrm{C}$ and at the 72 nd hour at $4^{\circ} \mathrm{C}$ were significantly different $(P<0.05)$ from the baseline value $(B V)$ while for the plasma specimens, the values differed significantly $(P<0.05)$ from the $B V$ after 6 hours at $32^{\circ} \mathrm{C}$. The plasma glucose level was found to be stable throughout the storage period of 3 days at $4^{\circ} \mathrm{C}$. Also, glucose concentration was found to be more stable in refrigerated samples than in those kept at ambient temperature $\left(32^{\circ} \mathrm{C}\right)$. Based on the findings of this study, reliable values for serum glucose can be obtained from samples kept at room temperature only if analysis is carried out within 2 hours of sample collection. However, when refrigerated, serum glucose results could still be relied upon for diagnosis if carried out within 48 hours post collection. Otherwise, plasma specimens are recommended for glucose estimation if little delay before analysis is anticipated since glucose was found to be more stable in plasma samples obtained from sodium fluoride anticoagulated blood.
\end{abstract}

Keywords: Glucose, Diabetes mellitus, Blood collection, Stability, Temperature

Introduction

Diabetes mellitus is a metabolic disease that results from absolute or relative deficiency of insulin, characterized by persistent increase in blood glucose levels above normal termed hyperglycemia and its attendant complications (Grundy et al., 1999). The population of people with diabetes mellitus, sometimes known as "the silent killer" is increasing at an alarming rate yearly. In Britain for instance, the population of elderly people with noninsulin dependent diabetes mellitus is estimated at between 3-6\% (Heil et al., 1987; Croxson et al., 1991). Nearly two decades ago, it was recognized in Britain that diabetes was neglected and that many patients were being denied specialist care. Several community studies of diabetes have also shown that these patients suffer a disproportionate burden of ill health and are responsible for increased economic and social demands on society (Alberti, 1991).

Management of diabetes mellitus includes assessing the impact of co-existing diseases and maintaining the patient's well being and quality of life. More emphasis, however, should be placed on laboratory tests, which require the co-operation of all medical personnel. Currently in medical practice a diagnosis of diabetes mellitus is not considered definitive or complete until information obtained from the patient's history and clinical examination are matched with the results of blood glucose estimations (Boulton, 1992). The results of blood glucose determinations can be strongly affected by the method of storage and handling of the blood samples between the time of collection and the time of analysis (Young and Bermes, 1999). Improperly handled or stored samples could generate results that may mislead the clinician into wrong judgment/diagnosis (Clark et al., 2003). As a result, the major challenge faced by clinical laboratories worldwide is ensuring the integrity and reliability of laboratory results. In addition to pathological processes, laboratory results are affected by certain pre-analytical, analytical and normal biological variations. But as analytical variations are being reasonably minimized by the development of new techniques, the relative contribution of preanalytical factors to spurious results has becomes a more dominant element in overall test variability (Navayanan, 1995; Young and Bermes, 1999).

Since prolonged contact of plasma or serum with cells is a common cause of spurious test results, plasma and serum should ideally be separated from cells as quickly as possible to prevent on going metabolism of cellular constituents as well as active and passive movement of analytes between the plasma or serum and cellular compartments (Ono et al., 1981; Murphy et al., 2000). Standard guidelines for blood sample handling and processing states that serum or plasma should be physically separated from contact with cells as soon as possible unless conclusive evidence shows that longer contact times do not contribute to result inaccuracy. A maximum time of two hours from the time of sample collection to the time of separation of serum and plasma from cells was also recommended (NCCLS Infobase, 1995; Young and Bermes, 1999).

It is generally recommended that glucose estimations in serum and plasma samples be carried out immediately upon sample collection, and if not immediately possible, that the specimens 
should be kept frozen until when the determinations are possible, but certainly within 24 hours (Nakashima et al., 1987; Young and Bermes, 1999). There is limited evidence though to suggest that serum and plasma glucose may not be stable when samples are kept for several hours or even days at ambient temperature condition. Due to a variety of experimental designs and variations in the ambient temperature conditions in different localities, the available reports regarding the stability of serum and plasma glucose at room/ambient temperature are, however conflicting.

In a developing country like ours, laboratory personnel are constantly faced with the problems of inconsistent power supply such that specimens for analysis are left on the laboratory bench at ambient temperature for several hours or even days before analysis can be done. In this study, we applied routine laboratory tests to investigate the changes in glucose levels in serum and plasma samples stored at $4^{\circ} \mathrm{C}$ and $32^{\circ} \mathrm{C}$ for a period of 3 days.

\section{Materials and Methods}

$10 \mathrm{ml}$ of blood was collected by venepuncture between 8-10 hours from 40 fasting patients diagnosed with diabetes mellitus at the Ebonyi State University Teaching Hospital (EBSUTH), Abakaliki, Nigeria after their oral informed consent was obtained. The blood samples were dispensed into each of the following collection tubes (a) half was added into a specimen bottle containing appropriate quantity of sodium fluoride and potassium oxalate (fluoride oxalate bottle) and (b) the other half was put into a clean dry plain bottle. The sample added into the fluoride oxalate bottle was centrifuged immediately after collection (3000 rpm for 5 minutes) and the plasma from it dispensed into a clean dry plain bottle. The sample collected into the clean dry plain bottle was allowed to stand at room temperature for 15 minutes to clot after which it was centrifuged at $3000 \mathrm{rpm}$ for 5 minutes and the serum from it separated into another clean dry plain bottle.

The serum and plasma samples from each patient were analyzed in duplicates immediately after separation from clot/blood cells to obtain the baseline fresh values against which other concentrations of future time-points were compared. The plasma and serum samples were then divided into two equal parts. One part was kept in a refrigerator at $4^{\circ} \mathrm{C}$, while the other was kept on the laboratory bench at room temperature (range of 30$34^{\circ} \mathrm{C}$, average of $32^{\circ} \mathrm{C}$ ). Further analysis on the samples were carried out in duplicates at 2 -hour intervals for the first 12 hours, then at 4 -hour intervals for another 12 hours, and later at 6-hour intervals for 24 hours and finally once after another 24 hours giving a total period of 3 days.

Glucose concentrations in the serum and plasma samples were determined by the glucose oxidase method (Washko and Rice, 1961). All determinations were carried out in duplicates each time and the average of the two results calculated. Results obtained from subsequent determinations were compared with the baseline fresh values. The influence of storage time and temperature on the measured quantity was examined using the repeat measure analysis of variance (ANOVA). The changes occurring on storage were calculated for glucose for individual patient and the result was expressed as a percentage of the initial value. Instability was defined as a change of $10 \%$ or more from the initial value provided ANOVA test was statistically significant $(P<0.05)$. A difference of $10 \%$ was selected because changes of less than this are unlikely to be clinically significant. The results obtained from the samples kept at $4^{\circ} \mathrm{C}$ were also compared with that obtained from samples kept at $32^{\circ} \mathrm{C}$ at each point of determination using student's t-test. Also, the serum and plasma results per unit time were compared with each other using the student's t-test. In this paper, the results are presented as mean percentage changes from the baseline value. The negative signs show percentage decreases below the baseline value.

\section{Results}

Table 1 shows the results obtained with serum samples separated immediately from clot and kept at both $4^{\circ} \mathrm{C}$ and $32^{\circ} \mathrm{C}$. On the whole, the glucose levels in the serum samples showed a decrease across the period of storage from the baseline value (zero hour) to the 72 nd hour when specimens were stored at both temperature conditions. The mean glucose concentration was stable for 48 hours when samples were kept at $4^{\circ} \mathrm{C}$. At ambient temperature, significantly lower $(\mathrm{P}<0.05)$ values from the baseline value were observed from the second hour of sample storage.

Table 1: The percentage change in glucose concentration in serum samples stored at varied temperature conditions

\begin{tabular}{|c|c|c|}
\hline \multirow{3}{*}{$\begin{array}{c}\text { Duration of } \\
\text { storage (hrs) } \\
2\end{array}$} & \multicolumn{2}{|c|}{$\begin{array}{l}\text { Percentage change in serum } \\
\text { glucose concentration }\end{array}$} \\
\hline & serum $\left(4^{\circ} \mathrm{C}\right)$ & serum $\left(32^{\circ} \mathrm{C}\right)$ \\
\hline & $-1.3 \pm 0.06$ & $-10.2 \pm 0.65$ \\
\hline 4 & $-1.9 \pm 0.24$ & $-11.1 \pm 0.76$ \\
\hline 6 & $-2.6 \pm 1.01$ & $-11.9 \pm 0.54$ \\
\hline 8 & $-3.4 \pm 0.75$ & $-13.1 \pm 0.92$ \\
\hline 10 & $-4.1 \pm 2.00$ & $-13.7 \pm 1.24$ \\
\hline 12 & $-4.8 \pm 0.71$ & $-15.2 \pm 1.05$ \\
\hline 16 & $-5.7 \pm 2.65$ & $-15.8 \pm 0.76$ \\
\hline 20 & $-6.1 \pm 2.29$ & $-16.6 \pm 1.90$ \\
\hline 24 & $-6.9 \pm 0.69$ & $-18.3 \pm 2.00$ \\
\hline 30 & $-7.5 \pm 1.37$ & $-18.9 \pm 0.81$ \\
\hline 36 & $-7.8 \pm 0.81$ & $-19.4 \pm 1.01$ \\
\hline 42 & $-8.1 \pm 0.95$ & $-19.9 \pm 0.91$ \\
\hline 48 & $-8.4 \pm 1.41$ & $-20.8 \pm 2.56$ \\
\hline 72 & $-10.5 \pm 1.54$ & $-23.4 \pm 2.19$ \\
\hline
\end{tabular}

The glucose concentration in the plasma samples also showed a decrease across the period of storage from the baseline value (zero hour) to the 72nd hour (Table 2). Statistical analysis showed that when plasma was kept at $4^{\circ} \mathrm{C}$, the mean glucose level was stable throughout the duration of the study. However, significant changes $(P<0.05)$ were observed from the 6th hour of storage when plasma samples were kept at ambient temperature. 
Table 2: The percentage change in glucose concentrations in plasma samples stored at varied temperature conditions

\begin{tabular}{|c|c|c|c|}
\hline \multirow{2}{*}{$\begin{array}{c}\begin{array}{c}\text { Duration of } \\
\text { storage (hrs) }\end{array} \\
2\end{array}$} & \multicolumn{3}{|c|}{$\begin{array}{l}\text { Percentage change in plasma } \\
\text { glucose concentrations }\end{array}$} \\
\hline & $-0.2 \pm 0.10$ & -6.9 & \pm 0.18 \\
\hline 4 & $-0.9 \pm 0.25$ & -8.5 & \pm 0.15 \\
\hline 6 & $-1.1 \pm 1.40$ & -10.6 & \pm 0.49 \\
\hline 8 & $-1.3 \pm 0.38$ & -11.4 & \pm 0.46 \\
\hline 10 & $-1.5 \pm 0.06$ & -12.5 & \pm 0.46 \\
\hline 12 & $-1.8 \pm 0.23$ & -13.2 & \pm 1.03 \\
\hline 16 & $-2.5 \pm 0.41$ & -13.9 & \pm 1.74 \\
\hline 20 & $-2.9 \pm 0.54$ & -14.7 & \pm 0.69 \\
\hline 24 & $-3.3 \pm 1.21$ & -15.8 & \pm 0.31 \\
\hline 30 & $-4.1 \pm 1.03$ & -16.5 & \pm 0.59 \\
\hline 36 & $-4.7 \pm 0.54$ & -16.9 & \pm 0.88 \\
\hline 42 & $-5.4 \pm 0.98$ & -17.4 & \pm 2.07 \\
\hline 48 & $-5.8 \pm 1.02$ & -17.8 & \pm 2.11 \\
\hline 72 & $-8.3 \pm 0.61$ & -20.9 & \pm 0.99 \\
\hline
\end{tabular}

\section{Discussion}

This study was conducted to determine the effects of storage temperature and time on the concentration of glucose in serum and plasma samples. The anticoagulant selected is the one commonly used in the determination of blood glucose levels. The present work demonstrates that glucose can be measured reliably in serum samples kept at room temperature if the assay is carried out within 2 hours of specimen collection and serum separation. Serum glucose level exhibit greater stability when samples are kept at $4^{\circ} \mathrm{C}$, hence reliable quantification of this analyte can still be carried out within 48 hours if serum is stored in the refrigerator. In plasma, reliable quantification of glucose requires that analysis be carried out within six hours of sample collection and plasma separation if the specimen is kept at ambient temperature condition. However, storing samples at $4^{\circ} \mathrm{C}$ showed that glucose level was stable throughout the duration of the study.

Previous researchers have studied the stability of clinical chemistry analytes in blood samples kept at different temperature conditions and different time-points. Investigating the effects of storage at refrigerator condition $\left(4-5^{\circ} \mathrm{C}\right)$ and room temperature $\left(23-25^{\circ} \mathrm{C}\right)$ on various biochemical constituents of camel sera, Saeed et al (1995) reported that at $4-5^{\circ} \mathrm{C}$, glucose in camel sera remained stable up to 6 days of keeping while at room temperature $\left(23-25^{\circ} \mathrm{C}\right)$, significant changes in glucose concentration occurred after 3 days. The study design was similar to that of the present work, with serum and plasma samples aliquoted immediately from clot/cells and stored under each temperature conditions up to the appropriate time before analysis.

In general, the outcome of this study has shown that reliable results for glucose assay can be obtained from both serum and plasma samples stored at both $4^{\circ} \mathrm{C}$ and $32^{\circ} \mathrm{C}$ for definite storage durations, with the refrigerated samples being more stable than the samples stored at $32^{\circ} \mathrm{C}$. The greater stability of glucose in refrigerated samples when compared to those kept at room temperature is in agreement with earlier reports on related studies though the room temperature of storage in these studies differ (Ono et al., 1981; Rehak and Chiang, 1988; Heins et al., 1995; Saeed et al.,1995; Dongbo et al., 1998; Bobby et al., 2002; Clark et al., 2003).

Again, glucose concentration decreased with increasing serum-clot / plasma-clot contact time (Bobby et al., 2002). It is well documented that glycolysis in cells consume glucose and cause a decrease in its level in blood during storage with a net gain in lactate and potassium ion concentrations in serum and plasma (Sunderman et al., 1956). As a result, Thoresen et al (1992) strongly recommended the practice of separating serum and plasma from clot / cells as promptly as possible to achieve improved stability of most analytes under test.

It can also be observed from this study that for both storage temperatures, the concentration of glucose in plasma was more stable than that observed for serum samples. This is in agreement with an earlier work by Chan et al (1989) who reported that glycolysis can be inhibited and glucose concentration stabilized by the use of sample collection tubes containing sodium fluoride as an additive. Thus, plasma is a preferred sample for glucose determination particularly when delay is inevitable.

In conclusion, it can thus be generally advised based on the results of this work that in order to obtain reliable results for blood glucose determination, serum samples stored at $4^{\circ} \mathrm{C}$ should be assayed within 72 hours of blood collection while for those stored at $32^{\circ} \mathrm{C}$ analysis should be carried out within 2 hours otherwise, the use of plasma samples is recommended if little delay before analysis is anticipated. Finally, recording the length of time from sample collection to analysis might allow appropriate adjustment to be made for the decrease in concentration of glucose over time.

\section{References}

Alberti, K. G.M.M. (1991). The health of the nation: role of diabetes. British Medical Journal, 303:769-772.

Bobby, L., Boyanton, J. and Kenneth, E. B. (2002). Stability studies of twenty-four analytes in human plasma and serum. Clinical Chemistry, 48:2242-2247.

Boulton, A.J. (1992). Update on long-term diabetic complications. In: Lewin, I. G. and Seymour, C.A., eds. Current themes in diabetic care. London. Royal College of Physicians of London, 45-53.

Chan, A.Y.W., Swaminathan, R. and Cockram, C.S. (1989). Effectiveness of sodium fluoride as a preservative of glucose in blood. Clin. Chem., 35:315-317.

Clark, S., Youngman, L.D., Palmer, A., Panish, S., Poto, R. and Collins, R. (2003). Stability of plasma analytes after delayed separation of whole blood - implications for epidemiological studies. International Journal of Epidemiology, 32, 125-130.

Croxson, S.C.M., Burden, A.C., Bodington, M. and Botha, J.L. (1991). The prevalence of 
diabetes in elderly people. Diabetic Med., $8: 28-31$.

Dongbo, J., Zhang, R.K., Elswick, W., Greg, M. and Jimmy, L.B. (1998). Effect of serum - clot contact time on clinical chemistry laboratory results. Clinical Chemistry, 44: $1325-1333$.

Grundy, S.M., Benjamin, I. and Burk, J. (1999). Diabetes and cardiovascular disease. A statement of health care professional. American Heart Association Circulation, 10: $1134-1146$.

Heil, H.A. W., Gatling, W., Mather, H.M., Thompson, A.V., Thorogood, M. and Fowler, G.H. (1987). The oxford community diabetes study: evidence for an increase in the prevalence of known diabetes. Diabetic Med., $4: 543$ - 559.

Heins, M., Heil, W. and Withold, W. (1995). Storage of serum or whole blood samples? Effects of time and temperature on 22 serum analytes. European J. Clin. Chem. Biochem., 33: 231 - 238.

Murphy, J.M., Browne, R.W., Hill, L., Bolalli, G.F., Abagnato, C., Bernino, F., Freudenheim, J., Muti, P. and Trevisan, M. (2000). Effects of transportation and delay in processing on the stability of nutritional and biochemical biomarkers. Nutrition and Cancer, 32:155 - 160. Nakashima, K., Takei, H., Nasu, Y. and Andoh, Y. (1987). D - mannose as a preservative of glucose in blood samples. Clinical Chemistry, 33: $708-710$.

Navayanan, S. (1995). Preanalytical aspects of coagulation testing. Haematologia, 86:1-6.

NCCLS Infobase 95, H 18 - A (1995). Procedures for the handling and processing of blood specimens; approved guideline. Villanova, PA: National Committee for Clinical Laboratory Standards (NCCLS) Publication.

Ono, T., Kitaguchi, K., Takehara, M., Shiba, M., Hayam, K. (1981). Serum constituent analysis: effect of duration and temperature of storage of clotted blood. Clinical Chemistry, 27: $35-38$.

Rehak, N.N. and Chiang, B. T. (1988). Storage of whole blood: effect of temperature on the measured concentration of analytes in serum. Clin. Chemistry, 34:2111-2114

Saeed, A., Afzal, M. and Akhtar, S. (1995). Effect of storage on some constituents of camel serum. Aust. Vet. J., 72 (6): 212 - 215.

Sunderman, F.W., Copeland, B.E., Macfate, R.P., Martens, V.E., Naumann, H.N. and Stevenson, G.E. (1956). Manual of American Society of Clinical Pathologists workshop on glucose. Am. J. Clinical Pathol., 26:1355 - 1372.

Thoresen, S.I., Havre, G.N., Morbeg, H. and Mowinckel, P. (1992). Effects of storage time on chemistry results from canine whole blood, heparinised whole blood, serum and heparinised plasma. Vet. Clin. Pathol., 21 (3): 88 - 94.

Washko, M.E. and Rice, E.W. (1961). Determination of glucose by an improved enzymatic procedure. Clinical Chemistry, 7: $542-545$.

Young, D.S. and Bermes, E.W. (1999). Specimen Collection and Processing: Sources of Biological Variation. In: Burtis, C.A and Ashwood, E.R. eds. Tietz Textbook of Clinical Chemistry. W.B. Saunders, Philadelphia. Pp42 - 72. 